Transportation Research Forum

A Multi-Objective Decision-Making Framework for Transportation Investments Author(s): Mashrur Chowdhury and Pulin Tan

Source: Journal of the Transportation Research Forum, Vol. 43, No. 1 (Spring 2004), pp. 91-104

Published by: Transportation Research Forum

Stable URL: http://www.trforum.org/journal

The Transportation Research Forum, founded in 1958, is an independent, nonprofit organization of transportation professionals who conduct, use, and benefit from research. Its purpose is to provide an impartial meeting ground for carriers, shippers, government officials, consultants, university researchers, suppliers, and others seeking exchange of information and ideas related to both passenger and freight transportation. More information on the Transportation Research Forum can be found on the Web at www.trforum.org. 


\section{A Multi-Objective Decision-Making Framework for Transportation Investments}

This paper presents a framework based on multi-objective optimization that can be used to generate and analyze the most desirable transportation investment options based on their objectives and constraints. The framework, which is based on the surrogate worth trade-off analysis, could be applied to both discrete or continuous decision-problem scenarios. In a discrete problem, a pre-defined set of alternatives is available, whereas continuous problems are not characterized by a pre-defined set of alternatives. This framework was applied with the data generated for a Capital Beltway Corridor investment study. The multi-objective decisionmaking framework was found to be adaptable to this typical investment case study.

\section{by Mashrur Chowdhury and Pulin Tan}

Transportation infrastructure decisions that optimize available resources and provide maximum benefits hold tremendous value to the transportation community. Decision makers attempt to reach their goals with welltimed and cost effective decisions that invest limited available resources according to future needs. Thus, it becomes increasingly important for decision makers to use objective tools to make proper investment choices.

Most decision-making scenarios in the transportation field are complex and include multiple and often conflicting objectives. These objectives are sometimes difficult to measure in monetary units alone, so traditional economic methods such as benefit-cost analysis may not be sufficient. If a policy maker has to decide between several mutually exclusive projects, benefit-cost analysis (CBA) is a useful economic tool for comparing projects and deciding which one is optimal. However, benefit-cost analysis requires a common unit of measurement, and the most typically used common unit is money. Therefore, all costs and benefits have to be expressed in monetary values, including the ones that are not so easily measurable such as air quality or safety. Ideally, all valuation of benefits should be measured based on directly observed behavior in the market. Unfortunately, it is not always possible to obtain market price for all benefits. Monetary valuation of benefits for benefit cost analysis may be difficult to do and unreliable in its result for many decision scenarios. Multiobjective analysis enables evaluation of the alternatives without the need to convert the objectives into monetary units. Additionally, multi-objective analysis is suitable for decision scenarios with multiple objectives where there is no single optimum solution. Multi-objective analysis provides a set of best solutions from a large set of available options, and provides an objective framework to eliminate a large number of possible options from any further consideration. At the same time, the framework provides an acceptable confidence bound where most desirable solutions are included in the set of best solutions.

Trading off labor costs versus environmental impacts is a challenge for all transportation projects. This and several other tradeoff scenarios comprise the multitude of 
criteria that a project must serve. To effectively reach a decision, a practitioner must utilize a decision-making framework.

A typical decision problem in transportation investment could be continuous, discrete, or a combination of both. In a discrete problem, a predefined set of alternatives is available. Many transportation investment projects have this characteristic, as project alternatives are selected from a number of possible alternatives (such as the selection of a project site from several possible sites). Continuous problems are not characterized by a pre-defined set of alternatives. Instead, for a continuous problem (such as miles of a particular road that need to be reconstructed), a mathematical model including decision variables, constraints, and multiple objective functions must be formulated to generate alternatives. The decision alternatives are not pre-defined in a continuous problem while a finite number exist in discrete problems.

Several previous studies applied different multi-objective methods to develop tools for making decisions in transportation-related issues, mostly for discrete problems. Many of these applications have been limited to a utility-based approach, rather than optimization-based approach, where various weights are assigned to different decision criteria. This type of decision-making approach was used in a study to identify the critical highway safety needs of special population groups (Dissanayake et al., 2002). In another utility-based approach, a software program was developed based on assigning weights to multiple objectives (NCHRP 2001). This utility-based approach could be used to evaluate transportation investment decisions on the basis of multiple goals, objectives, and measures.

The optimization-based approach is more objective than the utility-based approach for multi-objective decision analysis. The utilitybased approach is greatly reliant upon decision makers' input and criteria weighting, when final output and project selection could be influenced by personnel changes among the decision makers. The utility-based approach includes the decision maker's input as a part of developing the output. Input is sought through a set of questionnaires on the relative importance of selected measures of effectiveness (MOEs).

Haimes et al., applied a powerful optimization-based approach called the Surrogate Worth Trade-off (SWT) method for decision making in water resource systems (Haimes et al., 1975). The SWT method is used to generate surrogate worth functions. The method is composed of several consecutive phases in two major steps. The first step generates the non-dominated solutions using the constraint $(\varepsilon)$ method. In a non-dominated solution, any improvement of one objective can be achieved only at the degradation of the other. The constraint method is applied by optimizing any one of the objectives from $n$ number of objectives while all of the other objectives (n-1) are constrained to some value $(\varepsilon)$. The solution to the problem largely depends on the chosen $\varepsilon_{\mathrm{k}}$ vector, which is chosen between the minimum and maximum values of the $\mathrm{k}^{\text {th }}$ objective function.

The second step in the SWT method, known as the interactive process, includes direct interaction between the analyst and the decision maker. It can guide the decision maker to develop tradeoffs among objectives from the set of feasible solutions generated earlier to find the preferred solution. In many situations, transportation projects consider both economic factors and financial return on the investment and other factors such as quality of life and preservation of the environment. However, even though the generation of non-dominated solutions meets those criteria, decision makers need to make tradeoffs among such criteria.

In a study funded by the National Science Foundation, researchers developed a framework for evaluating the safety of alternative automobile designs in terms of the likelihood of crash occurrence and severity of likely injury (Haimes et al., 1994). The researchers used a multi-objective decision analysis approach called "Partitioned Multiobjective Risk Method" to develop the framework for evaluating the vehicle-based crash avoidance and worthiness technologies 
based on the expected and worst-case outcomes. This methodology permitted evaluation based on unconditional expected events as well as worst-case outcomes. The proposed framework included the SWT method to assess the preference of the decision maker/design engineer for competing design alternatives by interviewing him or her and communicating the possible outcomes and corresponding trade-offs.

A study by Chowdhury et al. (2000), "Multi-Objective Methodology for Highway Safety Resource Allocation,” presented an Interactive Multi-Objective Resource Allocation (IMRA) tool to help decision makers minimize the frequency and severity of vehicular crashes by selecting countermeasures and allocating resources optimally among various competing highways. This methodology also illustrated the tradeoff between various decision options and how to set priorities for a variety of potential crash countermeasures. The main objective of this research was to develop a tool that would aid in optimal resource allocation to improve highway safety. The IMRA tool supported interaction between the analyst and the decision maker that would help the decision maker select the best among various options.

An optimization-based approach, which addresses a combination of discrete and continuous problems for transportation investment analysis would be applicable to many investment decisions faced by pubic agencies. A case study that demonstrates the application of a multi-objective framework to actual transportation investment scenarios will provide motivation for real-world applications.

\section{OBJECTIVES}

The general objective of the research documented in this paper was to develop a multi-objective decision support system that would aid the decision-making process in a more systematic way. Specific objectives are listed below:

1. Develop a decision-making framework for selecting between multiple competing alternatives, continuous and/or discrete decision problems, while maximizing the desired and minimizing the undesired attributes.

2. Demonstrate the practical application of the methodology to actual transportation projects.

The proposed framework was applied with the data generated in a Capital Beltway Corridor transportation investment analysis (Maryland State Highway Administration 2001). The detailed case study follows a discussion of the framework.

\section{FRAMEWORK OF THE MULTI- OBJECTIVE METHODOLOGY}

The multi-objective framework includes a total of five steps. These steps are described below.

\section{Step 1. Identify Objectives}

The first activity is to identify the objectives to be measured. An objective is a statement about the desired state of the system under consideration. Objectives should be specific and cover the main goal or need, such as minimizing delay time, minimizing cost, and maximizing safety. Although some projects have a single objective, most transportation projects have multiple objectives. The analyst should consider all of the objectives in this process.

\section{Step 2. Select Measures of Effectiveness}

In this step, the objectives to be measured are defined. The effectiveness of each project alternative is measured according to the performance of these alternatives on all of the objectives specified in Step 1. 


\section{Step 3. Formulate a Mathematical Model}

The mathematical model is expressed as a mathematical function that represents the problem. The model is used to generate the value of decision variables and maximize or minimize the objective function subject to the specified constraints. If there are n-related decisions to be made, they are represented as decision variables $\left(\mathrm{x}_{1}, \mathrm{x}_{2}, \ldots, \mathrm{x}_{\mathrm{n}}\right)$ whose respective values are to be determined.

The appropriate measures of effectiveness, such as cost and travel time, are then expressed as a mathematical function of these decision variables. This function is called the objective function. For example, in the scenario given above the objective is to minimize cost and the decision variable $\left(\mathrm{x}_{\mathrm{i}}\right)$ is number of miles of road to build in area $\mathrm{i}$, where $i=1,2$, and 3 . The identification of the decision variable leads to essential answers to the questions the decision-maker is seeking. The constant value $\left(\mathrm{C}_{\mathrm{i}}\right)$ in this case may be the cost per mile of road built in area $\mathrm{i}$, where $\mathrm{i}=1,2$, and 3 . So, the objective function would be total cost, $C=C_{1} x_{1}+C_{2} x_{2}+C_{3} x_{3}$. Any restrictions on the values that can be assigned to these decision variables are also expressed mathematically, typically by means of inequality or equality. This mathematical restriction is called a constraint function.

A constraint function can restrict or reduce the number of alternatives. Common constraints in a transportation project are funding, right of way, and sometimes technology. For example, a region may have established a monetary limit per fiscal year for pavement programs, which is a budget constraint. A highway project in a metropolitan city has a right-of-way constraint to building new access, and an ITS project usually has a technological constraint to meet the specifications.

The decision variable $\left(x_{i}\right)$, objective function $\left(\mathrm{Z}_{\mathrm{j}}\right)$, and constraint function are used to represent the decision making problems by transforming them into a mathematical model. The decision variable is used to differentiate the mathematical model between a continuous and discrete problem. In a continuous problem, the decision variables will be continuous, such as the case where decision variable $\mathrm{x}_{\mathrm{ij}}$ represents miles of pavement type $\mathrm{i}$ in area $\mathrm{j}$ that will be built.

In a discrete problem, the decision maker simply decides which projects are to be chosen. The mathematical model for this type of problem uses the following decision variables:

(1) $\mathrm{x}_{\mathrm{i}}=\left\{\begin{array}{l}1 \text { if a project } \mathrm{i} \text { is selected, } \mathrm{i}=1,2, \ldots, \mathrm{m} \\ 0 \text { if project } \mathrm{i} \text { is not selected }\end{array}\right.$

Each $x_{i}$ is a binary variable, which has value of 0 or 1 . Binary variables are important in mathematical models because they represent a "yes" or "no" decision. In this case, a yes/ no decision means project $\mathrm{i}$ is or is not selected. After solving the mathematical model, the result will show that $\mathrm{x}_{\mathrm{A}}=1$ when project $A$ is selected. However if the result shows $x_{A}=0$, this means Project $A$ is not selected. An example is provided below where minimizing cost is the objective, subject to a set of constraints such as travel time and emissions that are less than some amount or number, $\varepsilon_{\mathrm{K}}$.

The mathematical model can be expressed as follows:

$$
\begin{gathered}
\text { (2) Minimize Cost, } \mathrm{Z}=\sum_{\mathrm{i}=1}^{\mathrm{m}} \mathrm{x}_{\mathrm{i}} * \mathrm{C}_{\mathrm{i}} \text {, } \\
\mathrm{C}_{\mathrm{i}}=\text { cost of project } \mathrm{i}
\end{gathered}
$$

(3) Subject to,

$$
\begin{aligned}
& \sum_{i=1}^{m} x_{i} * T_{i} \leq \varepsilon_{T}, \\
& T_{i}=\text { travel time of project } i \\
& \sum_{i=1}^{m} x_{i} * E_{i} \leq \varepsilon_{E}, \\
& E_{i}=\text { emissions from project } i
\end{aligned}
$$

where, $\mathrm{x}_{\mathrm{i}}=0$ or $1 . \varepsilon_{\mathrm{T}}$ and $\varepsilon_{\mathrm{E}}$ are constants, which are given or acceptable limit of travel time and emissions, respectively. 
Transportation Investments

Step 4. Generate Non-Dominated Solutions Using Surrogate Worth Tradeoff Method (SWT)

The SWT method is a multi-objective method used to generate a set of solutions and provide a technique that incorporates the decision maker's preferences in choosing the optimal solution. The following tasks are performed in this step:

\section{Construct a Payoff Table}

A payoff table (Table 1) consists of all objective values, when each objective is optimized subject to constraints. The first row in the table shows that the result $\mathrm{Z}_{1}\left(\mathrm{X}^{1}\right)$ represents the objective values for the first optimization run, $\mathrm{X}^{1}$, optimizing objective $\mathrm{Z}_{1}$. This process (optimization run) is repeated for a number of times equal to the number of objectives, $Z_{1}, Z_{2}, . ., Z_{p}$. For example, when the total number of objectives are three $\left(Z_{1}\right.$, $Z_{2}$, and $Z_{3}$ ), the optimization should be run three times to construct a payoff table. $\mathrm{X}^{\mathrm{P}}$ refers to the number of optimization runs for each $\mathrm{Z}$. The maximum ( $\max$ ) and minimum (min) refer to the optimization runs with the highest and lowest values of $\mathrm{Z}$.

The purpose of developing a payoff table is to help formulate the constraint model in the next task by determining the lower and upper bounds for the constraint e value, such as lower and upper bounds of cost or travel time constraints.

\section{Transform a Multi-Objective Problem into a Single Objective Problem}

This task involves considering one objective as primary and transforming other objectives as constraints. The general form of a multiobjective problem with $\mathrm{p}$ objectives and $\mathrm{m}$ constraints is shown below transformed into a constraint model (Cohon, 1978).

(4) Maximize or minimize $Z_{1}\left(X_{1}, X_{2}, \ldots, X_{n}\right)$, $Z_{2}\left(X_{1}, X_{2}, \ldots, X_{n}\right), \ldots, Z_{p}\left(X_{1}, X_{2}, \ldots, X_{n}\right)$

(5) subject to: $c_{1}\left(X_{1}, X_{2}, \ldots, X_{n}\right) \leq 0$,

$$
\begin{aligned}
& c_{2}\left(X_{1}, X_{2}, \ldots, X_{n}\right) \leq 0, \\
& \ldots, c_{m}\left(X_{1}, X_{2}, \ldots, X_{n}\right) \leq 0 \\
& X_{j} \geq 0, \quad j=1,2, \ldots, n
\end{aligned}
$$

The primary objective is $\left(Z_{h}\right)$ where the $h^{\text {th }}$ objective is chosen arbitrarily for following optimization model:

(6) Maximize $Z_{h}\left(X_{1}, X_{2}, \ldots, X_{n}\right)$

(7) Subject to:

$$
\begin{aligned}
& \mathrm{c}_{1}\left(\mathrm{X}_{1}, \mathrm{X}_{2}, \ldots, \mathrm{X}_{\mathrm{n}}\right) \leq 0 \\
& \mathrm{c}_{2}\left(\mathrm{X}_{1}, \mathrm{X}_{2}, \ldots, \mathrm{X}_{\mathrm{n}}\right) \leq 0 \\
& \ldots, \mathrm{c}_{\mathrm{m}}\left(\mathrm{X}_{1}, \mathrm{X}_{2}, \ldots, \mathrm{X}_{\mathrm{n}}\right) \leq 0 \\
& \mathrm{Z}_{\mathrm{k}}\left(\mathrm{X}_{1}, \mathrm{X}_{2}, \ldots, \mathrm{X}_{\mathrm{n}}\right) \leq \varepsilon_{\mathrm{k}} \\
& \mathrm{k}=1,2, \ldots, \mathrm{h}-1, \mathrm{~h}+1, \ldots, \mathrm{p} \\
& \mathrm{X}_{\mathrm{i}} \geq 0, \mathrm{j}=1,2, \ldots, \mathrm{n}
\end{aligned}
$$

Table 1: Payoff Table

\begin{tabular}{|c|c|c|c|c|}
\hline & $Z_{1}\left(\mathbf{X}^{\mathbf{k}}\right)$ & $\mathbf{Z}_{2}\left(\mathbf{X}^{\mathbf{k}}\right)$ & $\&$ & $\mathbf{Z}_{\mathbf{P}}\left(\mathbf{X}^{\mathbf{k}}\right)$ \\
\hline $\mathbf{X}^{\mathbf{1}}$ & $\mathrm{Z}_{1}\left(\mathrm{X}^{1}\right)$ & $\mathrm{Z}_{2}\left(\mathrm{X}^{1}\right)$ & $\&$ & $\mathrm{Z}_{\mathrm{p}}\left(\mathrm{X}^{1}\right)$ \\
\hline $\mathbf{X}^{\mathbf{2}}$ & $\mathrm{Z}_{1}\left(\mathrm{X}^{2}\right)$ & $\mathrm{Z}_{2}\left(\mathrm{X}^{2}\right)$ & $\&$ & $\mathrm{Z}_{\mathrm{p}}\left(\mathrm{X}^{2}\right)$ \\
\hline$\cdot$ & $\cdot$ & $\cdot$ & $\&$ & \\
\hline$\cdot$ & $\cdot$ & $\cdot$ & $\&$ & \\
\hline$\cdot$ & $\cdot$ & $\cdot$ & $\&$ & $\cdot$ \\
\hline $\mathbf{X}^{\mathbf{p}}$ & $\mathrm{Z}_{1}\left(\mathrm{X}^{\mathrm{p}}\right)$ & $\mathrm{Z}_{2}\left(\mathrm{X}^{\mathrm{p}}\right)$ & $\mathrm{Z}_{\mathrm{p}}\left(\mathrm{X}^{\mathrm{p}}\right)$ \\
\hline Max & Maximum value of $\mathrm{Z}_{1}\left(\mathrm{X}^{\mathrm{k}}\right)$ & Maximum value of $\mathrm{Z}_{2}\left(\mathrm{X}^{\mathrm{k}}\right)$ & & Maximum value of $\mathrm{Z}_{\mathrm{P}}\left(\mathrm{X}^{\mathrm{k}}\right)$ \\
\hline Min & Minimum value of $\mathrm{Z}_{1}\left(\mathrm{X}^{\mathrm{k}}\right)$ & Minimum value of $\mathrm{Z}_{2}\left(\mathrm{X}^{\mathrm{k}}\right)$ & & Minimum value of $\mathrm{Z}_{\mathrm{P}}\left(\mathrm{X}^{\mathrm{k}}\right)$ \\
\hline
\end{tabular}


Choose the Different Values of $\varepsilon_{k}$ from the Range of Minimum and Maximum Values for Each Objective (identified in Step 1)

The minimum and maximum values (for each column representing $\mathrm{Z}_{1}\left(\mathrm{X}^{\mathrm{k}}\right), \mathrm{Z}_{2}\left(\mathrm{X}^{\mathrm{k}}\right), \ldots, \mathrm{Z}_{\mathrm{p}}\left(\mathrm{X}^{\mathrm{k}}\right)$ in the payoff table) are derived from the payoff table. Feasible solutions to the constraint model will exist when $\varepsilon_{\mathrm{k}}$ is chosen between the minimum and maximum limit. The selection of constraint values, $\varepsilon_{\mathrm{k}}$, between the minimum and maximum limit, ensure that feasible solutions to the constraint problem could be generated. Each solution of the constraint model, with a selected combination of $\varepsilon_{\mathrm{k}}$ values between the minimum and maximum limit, will produce a non-dominated solution when all the objective constraints are binding.

Solve the Constraint Model for Every Combination of Values for the $\varepsilon_{k}$

The mathematical models (constraint model) with every combination of constraint values, $\varepsilon_{\mathrm{k}}$, are solved in this task to generate a set of non-dominated solutions. The model may be solved mathematically or by using commercially-available optimization software packages.

\section{Step 5. Choose the Preferred Solution}

The analyst presents the set of non-dominated solutions to the decision maker. The decision maker can choose a solution from the set of non-dominated solutions presented in this step.

\section{AN EXAMPLE APPLICATION OF THE MULTI-OBJECTIVE FRAMEOWRK}

The multi-objective decision-making framework discussed above was applied to the Capital Beltway Project in the metropolitan Washington, DC, area to demonstrate the practical application of the methodology to actual transportation projects. The data that were used for this example were based on a
Capital Beltway Corridor Study (Maryland Department of Transportation 2001).

\section{Project Description (Maryland Department of Transportation 2001)}

The Capital Beltway corridor is located in the metropolitan Washington, DC, area. It is the only circumferential route in the area, connecting many radial routes. A study conducted by the Maryland State Highway Administration found that the projected high increase in travel demand within the Beltway corridor in the year 2025 requires that both High Occupancy Vehicle (HOV) lanes and rail transit will be needed to handle the projected traffic. This Maryland study recommended that both HOV lane and rail transit alternatives be considered. HOV lanes and rail transit would perform different functions. It would serve different markets within the region and corridor. HOV lanes are added to concurrent lanes by adding one lane in each direction, providing commuters who are willing to carpool or take a bus with one lane on the Beltway that operates without too much congestion. It was concluded that even when rail transit is available, a large percentage of total trips in the corridor would be made by automobile. It was further concluded that the HOV lanes would help to improve travel conditions for HOV users. The Maryland Department of Transportation conducted separate impact studies for the HOV lane and the rail transit alternatives for the study area. The HOV lane corridor was divided into five segments. Rail transit was divided into six different alignments (P1, P2, P3, P4, P5, P6), in which $\mathrm{P} 1, \mathrm{P} 2$, and $\mathrm{P} 3$ were aligned for heavy rail and P4, P5, and P6 for light rail transit. Figure 1 shows a map of the study area.

\section{Decision Problem}

In this study case, the decision-making problem was solved using the decision framework presented in the previous section. The best solution was found by combining both HOV lane and rail transit options and deciding how many miles of HOV lane were 
Figure 1: Capital Beltway Corridor Case Study Area

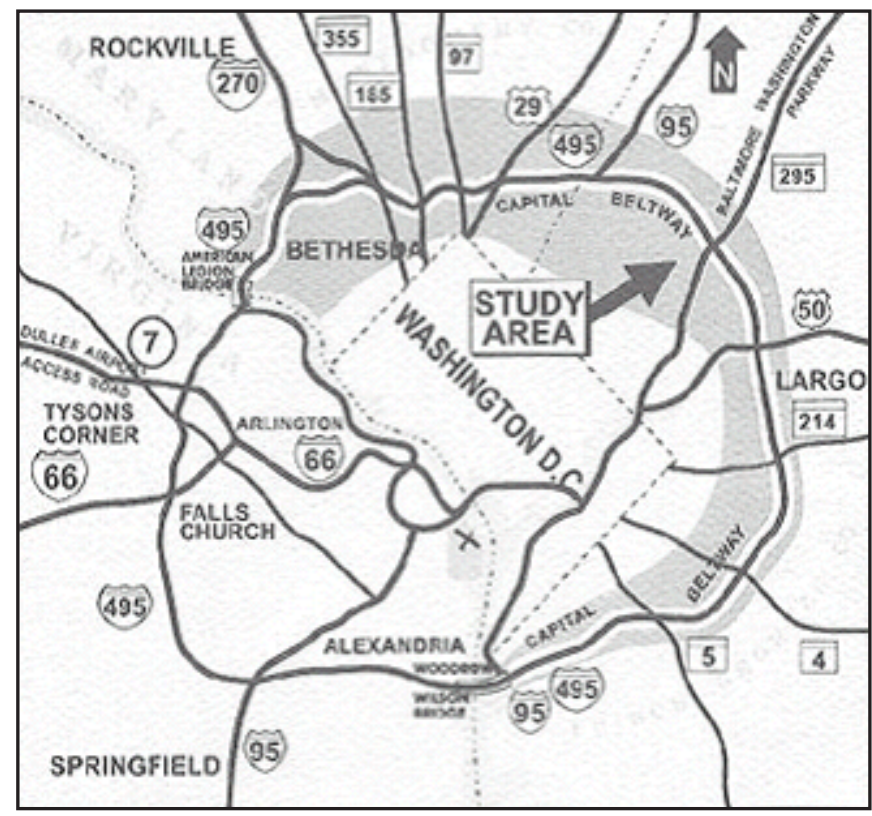

(Source: Maryland Department of Transportation 2001)

needed for each segment. Additionally, an alignment was to be selected with the corresponding light or heavy rail transit.

\section{Problem Solving}

Step 1. The identification of objectives is the first step in the decision-making process. The objectives for the Capital Beltway Corridor project were as follows (Maryland Department of Transportation 2001):

- Support regional mobility and address travel demand,

- Minimize incremental costs while maximizing transportation capacity, and

- Improve accessibility to existing and planned economic development areas and regional activity centers.

Step 2. Measure of Effectiveness used five different criteria to evaluate each alternative.

- Total costs

- Annual ridership
- Daily new ridership

- Public support, and

- Economic development.

Each HOV segment and transit alternative was evaluated and measured for their effectiveness. “Annual ridership” represents current ridership without any improvements and “daily new ridership" represents the increase in ridership because of improvements. "Public support" was measured based on comments received from the public. "Public support" scores ranged from “ 0 ” to “5," respectively, representing public opposed to the improvements (i.e., 0) to high public support (i.e., 5). "Economic development” was measured by forecasting whether the improvement will facilitate economic development by connecting major residential and/or employment activity centers. "Economic development" scores ranged from “ 0 ” to “ 5 ," respectively, representing the improvements will have no effect on economic development (i.e., 0) to 
the improvements will greatly facilitate economic development by connecting major residential and/or employment activity centers (i.e., 5). The measures of effectiveness are shown in Tables 2 and 3. These values were obtained for this case study from a Maryland Department of Transportation Capital Beltway Corridor Transportation study. Ridership values in Tables 2 and 3 are approximations as they are based on the assumption that they are not affected by the HOV length or type of transit selected.

Each of the criteria is measured in terms of cost, annual ridership, and daily new ridership. Public support and economic development are scored between 0 and 5 (negative to positive impact). This case study is basically a combination of a continuous (HOV) and a discrete (rail transit) problem.
The goal is to generate how many HOV miles need to be built and decide which rail transit alignment should be chosen.

The rail transit alternatives are based on alignment and rail transit type (light and heavy rail):

P1 = heavy rail transit alternative with alignment 1

P2 = heavy rail transit alternative with alignment 2

P3 = heavy rail transit alternative with alignment 3

P4 = light rail transit alternative with alignment 4

P5 = light rail transit alternative with alignment 5

P6 = light rail transit alternative with alignment 6

Table 2: Measures of Effectiveness for HOV Lanes 
Transportation Investments

Table 3: Measures of Effectiveness for Rail Transit

\begin{tabular}{|c|c|c|c|c|c|c|}
\hline \multicolumn{7}{|c|}{ TOTAL COST (IN MILLI ONS OF \$) } \\
\hline \multirow[b]{2}{*}{ SEGMENT } & \multicolumn{6}{|c|}{ ALIGNMENT } \\
\hline & P1 & P2 & P3 & P4 & P5 & P6 \\
\hline 1 & $\$ 2,136$ & $\$ 1,659$ & $\$ 2,136$ & $\$ 786$ & $\$ 857$ & $\$ 786$ \\
\hline 2 & $\$ 3,766$ & $\$ 3,019$ & $\$ 3,066$ & $\$ 1,254$ & $\$ 1,257$ & $\$ 1,430$ \\
\hline 3 & $\$ 2,599$ & $\$ 2,599$ & $\$ 2,599$ & $\$ 766$ & $\$ 630$ & $\$ 630$ \\
\hline 4 & $\$ 1,418$ & $\$ 1,418$ & $\$ 1,418$ & $\$ 470$ & $\$ 423$ & $\$ 423$ \\
\hline \multicolumn{7}{|l|}{ ANNUAL RIDERSHIP } \\
\hline & \multicolumn{6}{|c|}{ ALIGNMENT } \\
\hline SEGMENT & P1 & $\mathbf{P 2}$ & P3 & $\mathbf{P 4}$ & P5 & P6 \\
\hline 1 & $5,935,403$ & $4,382,770$ & $5,228,753$ & $3,507,785$ & $5,376,469$ & $3,492,959$ \\
\hline 2 & $33,810,886$ & $40,724,948$ & $28,604,913$ & $53,625,924$ & $30,363,296$ & $39,989,544$ \\
\hline 3 & $11,133,474$ & $10,531,544$ & $10,789,939$ & $10,251,554$ & $15,392,336$ & $12,122,800$ \\
\hline 4 & $4,522,762$ & $4,338,398$ & $4,317,583$ & $6,005,887$ & $9,396,844$ & $8,627,636$ \\
\hline \multicolumn{7}{|l|}{ DAILY NEW RIDERSHIP } \\
\hline & \multicolumn{6}{|c|}{ ALIGNMENT } \\
\hline SEGMENT & P1 & $\mathbf{P 2}$ & P3 & P4 & P5 & P6 \\
\hline 1 & 10,028 & 7,401 & 8,830 & 5,925 & 9,085 & 5,900 \\
\hline 2 & 30,847 & 32,054 & 26,090 & 42,332 & 27,696 & 31,822 \\
\hline 3 & 10,156 & 9,606 & 9,840 & 9,360 & 14,036 & 11,063 \\
\hline 4 & 7,636 & 7,325 & 7,291 & 10,148 & 15,870 & 14,578 \\
\hline \multicolumn{7}{|l|}{ PUBLIC SUPPORT } \\
\hline & \multicolumn{6}{|c|}{ ALIGNMENT } \\
\hline SEGMENT & P1 & $\mathbf{P 2}$ & P3 & P4 & P5 & P6 \\
\hline 1 & 4.00 & 5.00 & 4.00 & 4.00 & 4.00 & 4.00 \\
\hline 2 & 4.00 & 4.33 & 4.00 & 4.00 & 4.00 & 4.33 \\
\hline 3 & 4.00 & 4.00 & 4.00 & 4.00 & 4.00 & 4.00 \\
\hline 4 & 5.00 & 5.00 & 5.00 & 4.00 & 5.00 & 5.00 \\
\hline \multicolumn{7}{|c|}{ ECONOMIC DEVELOPMENT } \\
\hline & \multicolumn{6}{|c|}{ ALIGNMENT } \\
\hline SEGMENT & P1 & $\mathbf{P 2}$ & P3 & P4 & P5 & P6 \\
\hline 1 & 5.00 & 5.00 & 5.00 & 5.00 & 4.00 & 5.00 \\
\hline 2 & 4.00 & 4.67 & 4.00 & 4.33 & 4.50 & 4.33 \\
\hline 3 & 4.00 & 4.00 & 4.00 & 4.50 & 4.00 & 4.00 \\
\hline 4 & 4.00 & 4.00 & 4.00 & 4.00 & 4.00 & 4.00 \\
\hline
\end{tabular}

Step 3. Develop a Mathematical Formulation. There are two types of decision variables in this model. One, which is continuous, is for the HOV alternative, representing how many miles of road need to be built for each segment. The HOV alternative is divided into five different segments:

$\mathrm{Xi}=$ miles of road in segment $\mathrm{i}$,

$$
\mathrm{i}=1,2 \ldots, 5
$$

The second, which is discrete, is for rail transit representing a "yes" or "no" decision (1 = yes and $0=$ no) based on six different alignments (Pj with $\mathrm{j}=1,2, \ldots, 6)$ and type of rail transit; heavy rail (P1, P2, P3) or light rail (P4, P5, P6).

$$
\operatorname{Pj}=\left\{\begin{array}{l}
1, \text { if a project } \mathrm{j} \text { is selected } \\
\mathrm{j}=1,2, \ldots, 6 \\
0, \text { if a project is not selected. }
\end{array}\right.
$$


Five objectives are considered based on the MOEs selected earlier,

1. Minimize Total Cost,

$\mathrm{Z} 1=\sum_{\mathrm{i}=1}^{5} \mathrm{Xi} * \mathrm{Ci}+\sum_{\mathrm{j}=1}^{6} \mathrm{Pj} * \mathrm{Cj}$

2. Maximize Annual Ridership,

$\mathrm{Z} 2=\sum_{\mathrm{i}=1}^{5} \mathrm{Xi} * \mathrm{Ai}+\sum_{\mathrm{j}=1}^{6} \mathrm{Pj} * \mathrm{Aj}$

3. Maximize Daily New Ridership,

$\mathrm{Z3}=\sum_{\mathrm{i}=1}^{5} \mathrm{Xi} * \mathrm{Di}+\sum_{\mathrm{j}=1}^{6} \mathrm{Pj} * \mathrm{Dj}$

4. Maximize Public Support,

$\mathrm{Z} 4=\sum_{\mathrm{i}=1}^{5} \mathrm{Xi} * \mathrm{Si}+\sum_{\mathrm{j}=1}^{6} \mathrm{Pj} * \mathrm{Sj}$

5. Maximize Economic Development,

$\mathrm{Z} 5=\sum_{\mathrm{i}=1}^{5} \mathrm{Xi} * \mathrm{Ei}+\sum_{\mathrm{j}=1}^{6} \mathrm{Pj} * \mathrm{Ej}$

$\mathrm{Ci}=$ total cost per mile for $\mathrm{HOV}$ in segment $\mathrm{i}$

$\mathrm{Cj}=$ total cost for rail transit alternative $\mathrm{j}$

$\mathrm{Ai}=$ annual ridership per mile for $\mathrm{HOV}$ in segment $\mathrm{i}$

$\mathrm{Aj}$ = annual ridership for rail transit alternative $\mathrm{j}$

$\mathrm{Di}=$ daily new ridership per mile for $\mathrm{HOV}$ in segment i

$\mathrm{Dj}$ = daily new ridership for rail transit alternative $\mathrm{j}$

$\mathrm{Si}=$ score of public support per mile for $\mathrm{HOV}$

in segment $i$
Sj = score of public support for rail transit alternative $\mathrm{j}$

$\mathrm{Ei}$ = score of economic development per mile for $\mathrm{HOV}$ in segment $\mathrm{i}$

$\mathrm{Ej}$ = score of economic development for rail transit alternative $\mathrm{j}$

Constraints:

$\mathrm{X} 1 \leq 4.0$ miles

$\mathrm{X} 2 \leq 2.6$ miles

$\mathrm{X} 3 \leq 8.6$ miles

$\mathrm{X} 4 \leq 8.3$ miles

$\mathrm{X} 5 \leq 16.6$ miles

$\mathrm{P} 1+\mathrm{P} 2+\mathrm{P} 3+\mathrm{P} 4+\mathrm{P} 5+\mathrm{P} 6=1$

$\mathrm{Xi} \geq 0$

There is a restriction for $\operatorname{Pj}(\mathrm{j}=1,2, \ldots, 6)$ where the sum of $\mathrm{Pj}$ should equal 1, representing mutually exclusive alternatives (i.e., only one rail transit alternative needs to be chosen). In addition, the total HOV mileage should be less than or equal to the total segment length.

Step 4. Generate a non-dominated solution using the SWT, including the following tasks:

Construct a Payoff Table. The first task was to construct a payoff table (Table 4) by optimizing each of the five objectives separately (cost, annual ridership, daily new ridership, public support, and economic development) to obtain maximum or minimum values.

Table 4: Payoff Table of Capital Beltway Corridor

\begin{tabular}{|l|c|c|c|c|c|c|}
\cline { 3 - 7 } \multicolumn{2}{c|}{} & $\mathbf{Z}_{1}$ & $\mathbf{Z}_{2}$ & $\mathbf{Z}_{3}$ & $\mathbf{Z}_{4}$ & $\mathbf{Z}_{5}$ \\
\hline Min Cost & $\mathbf{X}^{\mathbf{1}}$ & $\$ 3,167,000,000$ & $60,528,944.40$ & $66,686.90$ & 17.00 & 16.50 \\
\hline $\begin{array}{l}\text { Max Annual } \\
\text { Ridership }\end{array}$ & $\mathbf{X}^{\mathbf{2}}$ & $\$ 4,497,745,000$ & $79,832,327.60$ & $89,523.10$ & 26.00 & 32.83 \\
\hline $\begin{array}{l}\text { Max Daily New } \\
\text { Ridership }\end{array}$ & $\mathbf{X}^{\mathbf{3}}$ & $\$ 4,497,745,000$ & $79,832,327.60$ & $89,523.10$ & 26.00 & 32.83 \\
\hline Max Public Support & $\mathbf{X}^{\mathbf{4}}$ & $\$ 9,916,745,000$ & $66,418,837.10$ & $78,142.70$ & 28.33 & 32.67 \\
\hline Max Economic Dev. & $\mathbf{X}^{\mathbf{5}}$ & $\$ 4,497,745,000$ & $79,832,327.60$ & $89,523.10$ & 26.00 & 32.83 \\
\hline & $\begin{array}{c}\text { Minimum } \\
\text { Value }\end{array}$ & $\$ 3,167,000,000$ & $60,528,944.40$ & $66,686.90$ & 17.00 & 16.50 \\
\cline { 2 - 7 } & $\begin{array}{c}\text { Maximum } \\
\text { Value }\end{array}$ & $\$ 9,916,745,000$ & $79,832,327.60$ & $89,523.10$ & 28.33 & 32.83 \\
\hline
\end{tabular}


Transportation Investments

Formulate a Constraint Model. The second task is to transform a multi-objective problem into a single objective problem using the constraint method. In this case, the maximized public support objective (Z4) was chosen as a primary objective and all other objectives (Z1, Z2, Z3, and Z5) are transformed as constraints, as shown below:

(8) Maximize Public Support,

$$
\mathrm{Z} 4=\sum_{\mathrm{i}=1}^{5} \mathrm{Xi} * \mathrm{Si}+\sum_{\mathrm{j}=1}^{6} \mathrm{Pj} * \mathrm{Sj}
$$

Constraints:

(9) $\mathrm{Z} 1=\sum_{\mathrm{i}=1}^{5} \mathrm{Xi} * \mathrm{Ci}+\sum_{\mathrm{j}=1}^{6} \mathrm{Pj} * \mathrm{Cj} \leq \mathrm{L} 1$

(10) $\mathrm{Z} 2=\sum_{\mathrm{i}=1}^{5} \mathrm{Xi} * \mathrm{Ai}+\sum_{\mathrm{j}=1}^{6} \mathrm{Pj} * \mathrm{Aj} \leq \mathrm{L} 2$

(11) $\mathrm{Z3}=\sum_{\mathrm{i}=1}^{5} \mathrm{Xi} * \mathrm{Di}+\sum_{\mathrm{j}=1}^{6} \mathrm{Pj} * \mathrm{Dj} \leq \mathrm{L} 3$

$$
\text { (12) } \mathrm{Z} 5=\sum_{\mathrm{i}=1}^{5} \mathrm{Xi} * \mathrm{Ei}+\sum_{\mathrm{j}=1}^{6} \mathrm{Pj} * \mathrm{Ej} \leq \mathrm{L} 5
$$

$\mathrm{X} 1 \leq 4.0$ miles

$\mathrm{X} 2 \leq 2.6$ miles

$\mathrm{X} 3 \leq 8.6$ miles

$\mathrm{X} 4 \leq 8.3$ miles

$\mathrm{X} 5 \leq 16.6$ miles

$\mathrm{P} 1+\mathrm{P} 2+\mathrm{P} 3+\mathrm{P} 4+\mathrm{P} 5+\mathrm{P} 6=1$

$\mathrm{Xi} \geq 0$

Choose Constraint Values. The L values (Table 5) are chosen arbitrarily from different values of the range of minimum and maximum for objectives 1, 2, 3, and 5 from the payoff table (Table 4). By choosing $\mathrm{L}$ between the minimum and maximum values, the feasible solutions for the above constraint problem can be generated. Each solution of the constraint model, with a selected combination of $L$ values between the minimum and maximum limit, will produce a non-dominated solution when all the objective constraints are binding.

Table 5: Constraint Values of Capital Beltway Corridor

\begin{tabular}{|c|c|c|c|}
\hline Constraint & \multicolumn{3}{|c|}{ Selected Constraint Values } \\
\hline $\mathbf{L}_{\mathbf{1}}$ & $\$ 5,416,915,000.00$ & $\$ 7,666,830,000.00$ & $\$ 9,916,745,000.00$ \\
\hline $\mathbf{L}_{\mathbf{2}}$ & $66,963,405.47$ & $73,397,866.53$ & $79,832,327.60$ \\
\hline $\mathbf{L}_{\mathbf{3}}$ & $74,298.97$ & $81,911.03$ & $89,523.10$ \\
\hline $\mathbf{L}_{\mathbf{5}}$ & 21.94 & 27.39 & 32.83 \\
\hline
\end{tabular}


Derive Solutions from the Model. The final task was to solve the constraint problem by maximizing the public support score subject to all constraints for every combination of values for $L_{1}, L_{2}, L_{3}$, and $L_{5}$. The model was solved for 80 runs with each run including a different combination of objective constraint values. The optimization process shows that $P_{j}=1$ when project $\mathrm{J}$ is selected. If the result shows $P_{j}=0$, project $J$ is not selected. Seven project alternatives (Y1, Y2, Y3, Y4, Y5, Y6, and Y7) were generated as combinations of $\mathrm{HOV}$ and rail transit projects by solving the constraint model presented in this step. The combinations are shown in Table 6.

In Table 6, Y1 represents the result of the optimization where HOV decision variable values of X1, X2, X3, X4, and X5 equaled 4, 2.6, 8.6, 8.3, and 16.6 miles, respectively and the rail transit decision variable values of $\mathrm{P} 1$, P2, P3, P4, P5, and P6 equaled 0, 1, 0, 0, 0, and 0 , respectively.

Based on the decision variable values generated in Table 6, the objective values (Z1, Z2, Z3, Z4, and Z5) for each alternative are shown in Table 7 . To show the relative importance of its objective values, these values are transformed (as shown in Table 8) into a 0-to-1 $\left(\mathrm{Z}_{\mathrm{p}}^{*}\right)$ scale using the equation below. This helps demonstrate their relative importance or utility, which could be communicated to the decision maker in a graphical format.
(13) $\mathrm{Z}_{\mathrm{p}}{ }^{*}=\left\{\mathrm{Z}_{\mathrm{p}}-\mathrm{Z}_{\mathrm{p}}(\min )\right\} /$

$$
\left\{Z_{p}(\max )-Z_{p}(\min )\right\}
$$

For example, the relative importance value of objective 1 ( $1^{*}$ ) for alternative $\mathrm{Y} 1$ is:

$$
\begin{aligned}
& \mathrm{Z}_{1} *=\{7666830000-5416915000\} / \\
& \quad\{9294426400-5416915000\}=0.58
\end{aligned}
$$

Step 5. The final stage of this decision framework is to select the preferred solution from the set of alternatives. The analyst could present the solved objective function values in a graphical format to the decision maker to demonstrate the relative trade-off for choosing between competing alternatives (Y1, Y2,.., Y7). This will help the decision maker select an alternative from the optimal set of alternatives generated through solving the decision model.

\section{CONCLUSIONS}

Most decision making in transportation agencies involves multiple objectives that often conflict and cannot be measured in monetary units. This makes the use of traditional investment analysis tools, such as benefit-cost analysis, difficult. This study presented a multi-objective framework that could be applied under different decision scenarios in transportation investment processes. Instead of transforming all different

Table 6: Generated Alternatives and Associated Decision Variables from the Solved Constraint Model

\begin{tabular}{|c|c|c|c|c|c|c|}
\hline \multirow{2}{*}{$\begin{array}{c}\text { Project } \\
\text { Selection }\end{array}$} & \multicolumn{7}{|c|}{ HOV } & \multirow{2}{*}{$\begin{array}{c}\text { Rail } \\
\text { Transit }\end{array}$} \\
\hline & X1 & X2 & X3 & X4 & X5 & P2 \\
\hline Y1 & 4.00 & 2.60 & 8.60 & 8.30 & 16.60 & P2 \\
\hline Y2 & 2.01 & 2.60 & 0.00 & 0.00 & 0.00 & P2 \\
\hline Y3 & 4.00 & 2.60 & 8.60 & 2.94 & 0.00 & P2 \\
\hline Y4 & 4.00 & 2.60 & 2.06 & 0.00 & 16.60 & P5 \\
\hline Y5 & 4.00 & 2.60 & 8.60 & 4.28 & 0.00 & P5 \\
\hline Y6 & 2.65 & 2.60 & 0.00 & 0.00 & 0.00 & P6 \\
\hline Y7 & 4.00 & 2.60 & 8.60 & 8.30 & 16.60 & \\
\hline
\end{tabular}


Table 7: Objective Value of Generated Solution of Capital Beltway Corridor

\begin{tabular}{|c|c|c|c|c|c|}
\hline \multirow{2}{*}{$\begin{array}{c}\text { Project } \\
\text { Alternative }\end{array}$} & \multicolumn{5}{|c|}{ Objective } \\
\cline { 2 - 6 } & $\mathbf{Z}_{\mathbf{1} \text { (min cost) }}$ & $\mathbf{Z}_{\mathbf{2} \text { (max annual ridership) }}$ & $\mathbf{Z}_{\mathbf{3} \text { (max daily new ridership) }}$ & $\mathbf{Z}_{\text {4(max public support) }}$ & $\mathbf{Z}_{\text {5(max economic development) }}$ \\
\hline Y1 & $7,666,830,000$ & $68,183,307.3$ & $81,035.6$ & 27.9 & 32.5 \\
\hline Y2 & $7,666,830,000$ & $60,954,471.3$ & $61,376.5$ & 21.1 & 21.9 \\
\hline Y3 & $7,666,830,000$ & $64,630,147.7$ & $74,572.9$ & 24.7 & 27.4 \\
\hline Y4 & $9,294,426,400$ & $63,682,935.7$ & $68,904.4$ & 24.8 & 27.4 \\
\hline Y5 & $5,416,915,000$ & $64,989,685.3$ & $79,309.7$ & 24.4 & 27.4 \\
\hline Y6 & $5,416,915,000$ & $61,433,500.7$ & $66,446.4$ & 20.8 & 21.9 \\
\hline Y7 & $7,666,830,000$ & $68,183,307.3$ & $81,035.6$ & 27.9 & 32.5 \\
\hline
\end{tabular}

Table 8. Objective Value Scale of Capital Beltway Corridor

\begin{tabular}{|c|c|c|c|c|c|}
\hline \multirow{2}{*}{$\begin{array}{c}\text { Project } \\
\text { Alternative }\end{array}$} & \multicolumn{5}{|c|}{ Objective } \\
\cline { 2 - 6 } & $\mathbf{Z}_{\mathbf{1}(\min )}$ & $\mathbf{Z}_{\mathbf{2 ( \operatorname { m a x } )}}$ & $\mathbf{Z}_{\mathbf{3}(\max )}$ & $\mathbf{Z}_{\mathbf{4 ( \operatorname { m a x } )}}$ & $\mathbf{Z}_{\mathbf{5 ( \operatorname { m a x } )}}$ \\
\hline Y1 & 0.58 & 1.00 & 1.00 & 1.00 & 1.00 \\
\hline Y2 & 0.58 & 0.00 & 0.00 & 0.03 & 0.00 \\
\hline Y3 & 0.58 & 0.51 & 0.67 & 0.54 & 0.51 \\
\hline Y4 & 1.00 & 0.38 & 0.38 & 0.56 & 0.51 \\
\hline Y5 & 0.00 & 0.56 & 0.91 & 0.51 & 0.51 \\
\hline Y6 & 0.00 & 0.07 & 0.26 & 0.00 & 0.00 \\
\hline Y7 & 0.58 & 1.00 & 1.00 & 1.00 & 1.00 \\
\hline
\end{tabular}

project alternatives or objectives into monetary values, these alternatives or objectives can be approached on an equal basis in their own measures of effectiveness, either in monetary or non-monetary terms. The proposed framework permits objective decision analysis for any transportation investment.

The proposed framework addresses both discrete or continuous decision problems and a combination of the two. This makes the proposed framework applicable to a wide range of decisions that are required in transportation investment scenarios.
The application of the proposed framework in the Capital Beltway Corridor investment study demonstrated the suitability of the methodology. The framework presented in this study could be considered by public agencies as an alternative or complement to traditional economic analysis and integrated with agency funding processes and management systems. The proposed decisionanalysis framework, which is general in nature, could also be applied to other transportation areas, such as aviation, rail, and water. 


\section{References:}

Chowdhury, Mashrur, Nicholas Garber, and Duan Li. "Multi-objective Methodology for Highway Safety Resource Allocation.” American Society of Civil Engineers Journal on Infrastructure Systems, 6(4), (2000): 138-144.

Cohon, Jared L. Multi-objective Programming and Planning, Academic Press, London, 1978.

Dissanayake, Sunanda, J. Lu, X. Chu, and P. Turner. "Use of Multi-criteria Decision Making to Identify the Critical Highway Safety Needs of Special Population Groups.” Transportation Research Record, No. 1693, (2002): 13-17.

Haimes, Y., J. Eisele, M. Chowdhury, P. Kuczzminski, R. Schwing, N. Garber and D. Li, Improvement of Highway Safety Through Optimal Vehicle Design: Fault-Tree and Multiobjective Analysis, National Science Foundation (NSF) Project SES-9308247 Report, 1994.

Haimes, Y.Y., W. Hall and H. Freedman. Multi-objective Optimization in Water Resources Systems, Elsevier Scientific, New York, 1975.

Maryland Department of Transportation, Capital Beltway Corridor Transportation Study, Maryland, 2001.

National Cooperative Highway Research Program (NCHRP). Development of a Computer Model for Multimodal, Multicriteria Transportation Investment Analysis, Research Results Digest, Number 258, 2001.

Mashrur A. Chowdhury is an assistant professor in the Department of Civil and Environmental Engineering and Engineering Mechanics at the University of Dayton. Chowdhury received his Ph.D. in Civil Engineering from the University of Virginia. He is a registered professional engineer in Ohio and the District of Columbia.

Pulin Tan was a graduate research assistant in the Department of Civil and Environmental Engineering and Engineering Mechanics and the University of Dayton. She received her M.S. in Civil Engineering from the University of Dayton in May 2003. 